\title{
Dendritic Spine Alterations in Neocortical Pyramidal Neurons following Postnatal Neuronal Nogo-A Knockdown
}

\author{
A.D. Pradhan ${ }^{\text {b,f, } 1}$ A.M. Case ${ }^{\text {b, } f}$ R.G. Farrer ${ }^{f}$ S.Y. Tsai ${ }^{f} \quad$ J.L. Cheatwood ${ }^{a}$ \\ J.L. Martin e G.L. Kartje ${ }^{b-d, f}$ \\ ${ }^{a}$ Department of Anatomy, Southern Illinois University School of Medicine, Carbondale, III., b Neuroscience \\ Program, Departments of ${ }^{\mathrm{C}}$ Molecular Pharmacology and Therapeutics, and d Neurology, ${ }^{\mathrm{e} C a r d i o v a s c u l a r}$ Institute, \\ Department of Medicine, Loyola University Medical Center, Maywood, III., and f Neurology and Research Services, \\ Hines VA Hospital, Hines, III., USA
}

\section{Key Words}

Cerebral cortex $\cdot$ Adeno-associated virus $\cdot$ Short hairpin

RNA $\cdot$ Pyramidal neuron

\begin{abstract}
The myelin-associated protein Nogo-A is a well-known inhibitor of axonal regeneration and compensatory plasticity, yet functions of neuronal Nogo-A are not as clear. The present study examined the effects of decreased levels of neuronal Nogo-A on dendritic spines of developing neocortical neurons. Decreased Nogo-A levels in these neurons resulted in lowered spine density and an increase in filopodial type protrusions. These results suggest a role for neuronal NogoA in maintaining a spine phenotype in neocortical pyramidal cells.

Copyright $\odot 2010$ S. Karger AG, Basel
\end{abstract}

1 Present affiliation:

Department of Cardiology

Heart and Vascular Institute, Pennsylvania State HMC

Hershey, PA 17111 (USA)

\section{KARGER}

Fax +4161306 1234

E-Mail karger@karger.ch

www.karger.com
(C) 2010 S. Karger AG, Basel

Accessible online at: www.karger.com/dne

\section{Introduction}

The Nogo-A protein is a potent suppressor of neuronal outgrowth in the intact [1] and injured [2] central nervous system (CNS). Anti-Nogo-A immunotherapy after ischemic stroke in the adult rat induces axonal remodeling and functional recovery, and also leads to enhanced dendritic arborization and increased spine density in pyramidal neurons of the contralesional neocortex [3]. This finding of effects on spine density led us to investigate the role of Nogo-A in neocortical pyramidal neurons of the undamaged CNS, to determine if neuronal Nogo-A plays a role in dendritic spine development.

Earlier studies of neuronal Nogo-A have shown that expression levels are high in embryonic and neonatal development, particularly in populations such as Purkinje neurons of the cerebellum, pyramidal cells of the hippocampus, and in layer $\mathrm{V}$ pyramidal neurons of the sensorimotor cortex of the rodent [4-6]. Temporal expression patterns of Nogo-A throughout embryonic and neonatal development indicate that the molecule may

A.D.P. and A.M.C. contributed equally to this work.

Alicia M. Case

Research Service 151, Building 1, Room D400

Edward Hines VA Hospital, 5000 South 5th Ave.

Hines, IL 60141 (USA)

Tel. +1 708202 5579, Fax +1 708202 4654, E-Mail acase@lumc.edu 
participate in processes beyond inhibition of outgrowth and plasticity $[7,8]$. Indeed, recent work has suggested that Nogo-A is involved in neuronal branching, neuronal migration, and synapse stabilization [5, 9]. Specifically, cultured neurons from mice lacking expression of Nogo-A as well as the other Nogo isoforms B and C showed enhanced axonal branching in vitro [5]. In vivo, these mice displayed delayed interneuron migration during neocortical development [5]. Also, Nogo-A overexpression in cerebellar Purkinje neurons from postnatal day 7 (P7) to adulthood led to a decrease in stability of inhibitory synaptic contacts, a decreased number of synapses overall, and deficits in motor learning and coordination [9].

In order to directly assess the role of neuronal Nogo-A in dendritic spine development in vivo, we used a Nogo-A knockdown approach mediated by RNA interference, in the form of short hairpin RNA (shRNA), delivered by an adeno-associated virus serotype 2/8 (AAV2/8). AAV2/8 is ideally suited for targeting neuronal Nogo-A because approximately $95 \%$ of transduced cells in the CNS are neurons $[10,11]$. Transduction of oligodendrocytes, the other major cell type in the intact CNS that is Nogo-A positive, is negligible [12]. Our study demonstrates that shRNA knockdown of neuronal Nogo-A in early postnatal development leads to decreased dendritic spine density and an increase in filopodia in adult neocortical pyramidal neurons.

\section{Materials and Methods}

\section{Construction of AAV Plasmids}

The recombinant AAV plasmid (pAAV)-enhanced green fluorescent protein (EGFP) construct was generated by inserting the EGFP cDNA into the XhoI and BglII restriction sites in pAAVMCS (Stratagene, Inc.). For pAAV-shNogo856, three different siRNA sequences targeted against the amino portion of Nogo-A were screened for efficiency in vitro. Antisense-loop-sense oligonucleotides corresponding to nucleotides $856-874$ of rat Nogo-A cDNA sequence (shNogo856) were synthesized, annealed and subcloned into the Bbs1 and Xbal sites of the mU6pro plasmid as described [13]. The U6-shNogo856 fragment was then inserted into the pAAV-EGFP plasmid at the MluI site upstream of the CMV promoter. The control hairpin siRNA, shLuc, targeted against Photinus pyralis luciferase, was constructed by annealing and inserting the described oligonucleotides into the BamH1/EcoR1 sites on the pZac2.1-U6-luc-CMV-Zsgreen [14]. All plasmids were verified by sequencing and purified by Maxiprep (Qiagen).

\section{Cell Culture and Transfection}

Neuroblastoma B104 and HEK293 cells were grown in Dulbecco's modified Eagle's medium (Invitrogen, Life Technologies,
Inc.) containing $10 \%$ fetal bovine serum and gentamicin. For dose-responsive knockdown, cells were also transfected with $2 \mu \mathrm{g}$ Nogo-A plasmid. Plasmids were transfected using the calcium phosphate technique (Virapack transfection kit; Stratagene) or, in the case of HEK 293 cells, Polyfect Transfection Reagent in accordance with manufacturer's instructions (Qiagen). Cells were lysed and harvested at 3 days after transfection. All experiments were replicated a minimum of three times.

\section{Immunoblotting}

SDS-PAGE and Western blotting were performed as previously described [15]. Briefly, cell lysates were electrophoresed through an SDS-polyacrylamide gel and transferred to a polyvinylidene difluoride membrane. Membranes were incubated overnight at $4^{\circ} \mathrm{C}$ with the primary antibody $(1: 800$ for $11 \mathrm{C} 7,1: 5,000$ for antiGAPDH antibody). The membrane was washed with PBS and incubated with an alkaline phosphatase-conjugated secondary antibody (1:5,000; Pierce) for $2 \mathrm{~h}$.

\section{Virus Production, Purification, and Titering}

Viruses were constructed using the plasmids described above and following the method of Zolotukhin et al. [16] with the following provisions. Each construct was cotransfected in AAV-293 cells (Stratagene) with p5E-VD282, which expresses the replication gene of AAV2 and capsid gene of AAV8, and pHelper (Stratagene) plasmids. Cotransfection was carried out using the Virapack transfection kit (Stratagene). After purification by an iodixanol step gradient, preparations were concentrated and desalted utilizing multiple cycles of centrifugation through Biomax $100 \mathrm{~K}$ concentrators (Millipore, Bedford, Mass., USA) with PBS as the diluent. AAV2/8-EGFP was either purchased from University of Pennsylvania vector core or generated in house. Titer was assessed by serial dilutions of virus and infection of HT1080 cells. After $72 \mathrm{~h}$, GFP-positive cells were counted, and the average number of infected cells ranged from $5 \times 10^{5}$ to $1 \times 10^{6} / \mathrm{ml}$.

\section{Animals}

All animal procedures were approved by the Institutional Animal Care and Use Committee of Loyola University and Hines Veteran Affairs Hospital and conform to the National Institutes of Health guidelines. Animals were housed in a temperature- and humidity-controlled room on a 12-hour light:dark cycle.

On P3, male rat pups were randomly assigned to one of three experimental groups: (a) control AAV-EGFP group $(\mathrm{n}=7)$, (b) control AAV-shLuc group $(\mathrm{n}=7)$ or $(\mathrm{c})$ knockdown AAVshNogo856 group $(n=9)$. For each group, rats were cryoanesthetized as described previously [17] and placed in a neonatal stereotactic apparatus. A small vertical incision was made in the midline of the scalp, the skin was retracted, and a skull flap was gently removed. Stereotactic injection coordinates were $0.5 \mathrm{~mm}$ anterior, $1.5 \mathrm{~mm}$ lateral and $1 \mathrm{~mm}$ ventral to bregma. Virus-containing solution was slowly delivered into the brain at a rate of $0.5 \mu \mathrm{l} / \mathrm{min}$ using a $10-\mu \mathrm{l}$ Hamilton syringe equipped with a 30 -gauge needle, for a total infusion volume of $5 \mu$ l. The needle was left in place for $5 \mathrm{~min}$ and removed slowly. The skull flap was then replaced and the overlying skin was sutured. Neonates were rewarmed under a lamp, and returned to the dam after regaining normal color and activity. Litters were culled to 8-10 pups, weaned at postnatal P21, and housed in groups of four for the duration of the study. Six weeks after AAV injection, rats were given an over- 
Fig. 1. Nogo-A knockdown. a Neuroblastoma cells transfected with pAAVshNogo856 showed reduction in Nogo-A immunoreactivity, compared to pAAVEGFP-transfected cells. b Results from a expressed as percent of control (GAPDH), demonstrated more than $95 \%$ decreased Nogo-A immunoreactivity (*** $\mathrm{p}<0.001$, ANOVA, mean + SEM).
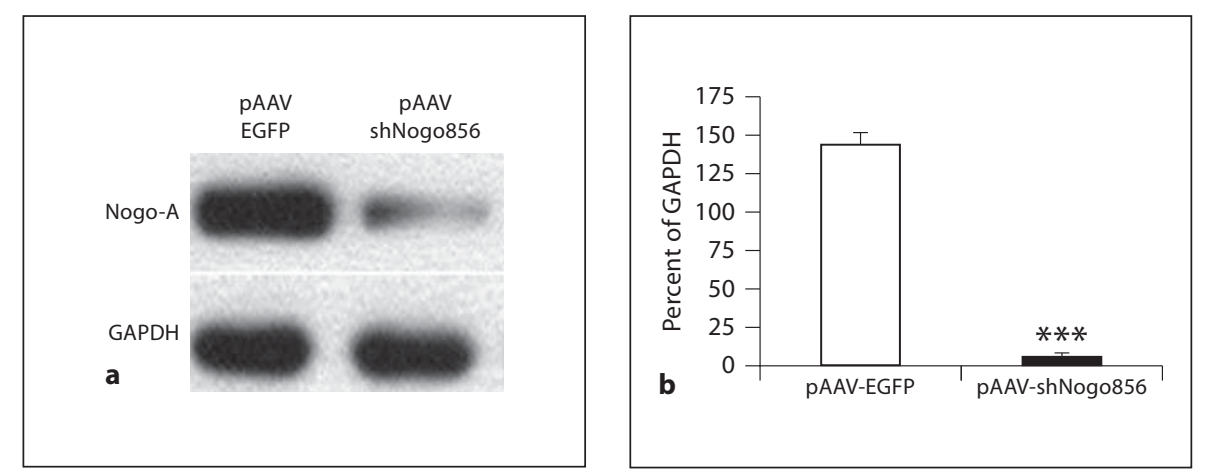

dose of sodium pentobarbital $(100 \mathrm{mg} / \mathrm{kg})$ and transcardially perfused with saline followed by $4 \%$ paraformaldehyde. Brains were removed and post-fixed for $1 \mathrm{~h}$.

Immunohistochemical Confirmation of Nogo-A Knockdown

To confirm Nogo-A knockdown in vivo, brains were cryoprotected for $24 \mathrm{~h}$ in $30 \%$ sucrose solution before being frozen and stored at $-80^{\circ} \mathrm{C}$. Cryostat sections $(50 \mu \mathrm{m})$ were collected and incubated in blocking solution containing $10 \%$ normal goat serum in PBS for $1 \mathrm{~h}$ at $23^{\circ} \mathrm{C}$. After blocking, sections were incubated in a primary antibody solution containing PBS, 5\% normal goat serum, and monoclonal anti-Nogo-A antibody $11 \mathrm{C} 7$ (1:800; Novartis) overnight at $4^{\circ} \mathrm{C}$. Ten to twelve 0.5 - $\mu \mathrm{m}$-thick stacks were taken at $\times 63$ magnification on a laser-scanning confocal microscope. Three animals were examined per group, with at least fifty EGFP-positive cortical cells counted per animal. Of these transduced cells, the total number of Nogo-A-immunopositive cells was also counted. The number of doublelabeled cells was expressed as a percentage of the total number of transduced cells.

\section{Dendritic Spine Imaging and Analysis}

150 - $\mu \mathrm{m}$-thick sections were cut on a vibratome, mounted onto slides, and coverslipped. Thin optical sections were obtained using a Zeiss 510 laser scanning microscope, under $\times 63$ objective (numerical aperture 1.2) and $\times 2$ zoom. Pyramidal neurons in layer $\mathrm{V}$ of the primary sensorimotor cortex were imaged. The 2nd-order dendrite originating from the apical shaft was captured, and the first $10-\mu \mathrm{m}$ segment from the branch point was excluded. Three to five pyramidal neurons were imaged for a total of five to eight 2 nd-order dendrites for every animal. To determine the density of dendritic spines, the total number of spines in a $10-\mu \mathrm{m}$ length of dendrite was counted using NIH Image J software [18]. For morphology analysis, maximum head diameter and length were measured for each spine. Filopodia dendritic protrusions that did not show a clearly identifiable spine head, as described in [19], were counted and each listed separately.

\section{Statistical Analyses}

Prism 4 for Windows (GraphPad Software, Inc.) was used to analyze all data via one-way, two-tailed ANOVA with Bonferroni post-hoc testing. $\mathrm{p}<0.05$ was regarded as statistically significant.

Neuronal Nogo-A Influences Developing Spines

\section{Results}

Recombinant Virus, AAV-shNogo856, Mediated in vitro and in vivo Nogo-A Gene Knockdown in Cortical Neurons

To first test for a decrease in Nogo-A levels, neuroblastoma B104 cells were transfected with hairpin siRNA against Nogo-A (shNogo856). Homogenates displayed a more than $95 \%$ decrease in Nogo-A immunoreactivity, as assayed by Western blot (fig. 1). In confirmation of this, HEK-293 cells cotransfected with both Nogo-A and shNogo 856 plasmids displayed doseresponsive loss of Nogo-A (online suppl. fig. 1; www. karger.com/doi/10.1159/000309135).

Neocortical layer V pyramidal neurons were transduced following AAV injection into the presumptive primary sensorimotor cortex of $\mathrm{P} 3$ rat pups. While we did occasionally observe astrocytes transduced by AAV2/8, as identified by EGFP, the majority of cells transduced had a neuronal morphology. Pyramidal neurons transduced with the control vector, AAV-EGFP, showed immunoreactivity for Nogo-A, while very few pyramidal neurons from the AAV-shNogo856 group showed any Nogo-A immunostaining (fig. 2). The average percent of double-labeled cortical cells was $38.33 \pm 3.75$ in the control vector group, and $9.73 \pm 7.66$ in the AAVshNogo856-transduced group ( $\mathrm{p}<0.03$; data not shown); in the transduced neurons there was a $75 \%$ decrease in the number of Nogo-A immunopositive cells.

\section{Neuronal Nogo-A Knockdown in vivo Results in Reduced Dendritic Spine Density}

After a 6-week survival period, no significant difference in spine density was detected between control groups transduced with either AAV-EGFP or another control virus, AAV-shLuc ( $p>0.05$; fig. 3). EGFP-positive layer V 

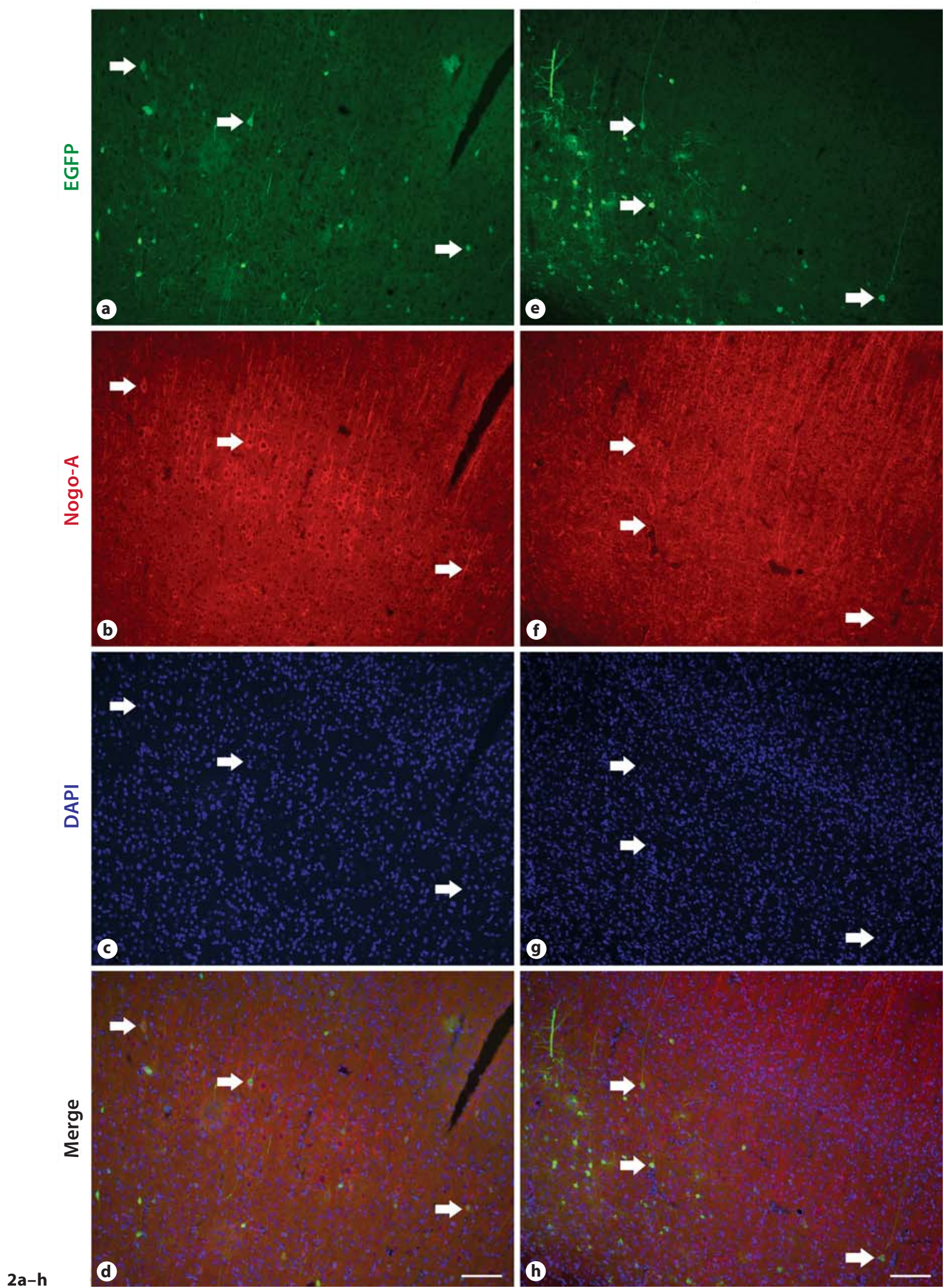

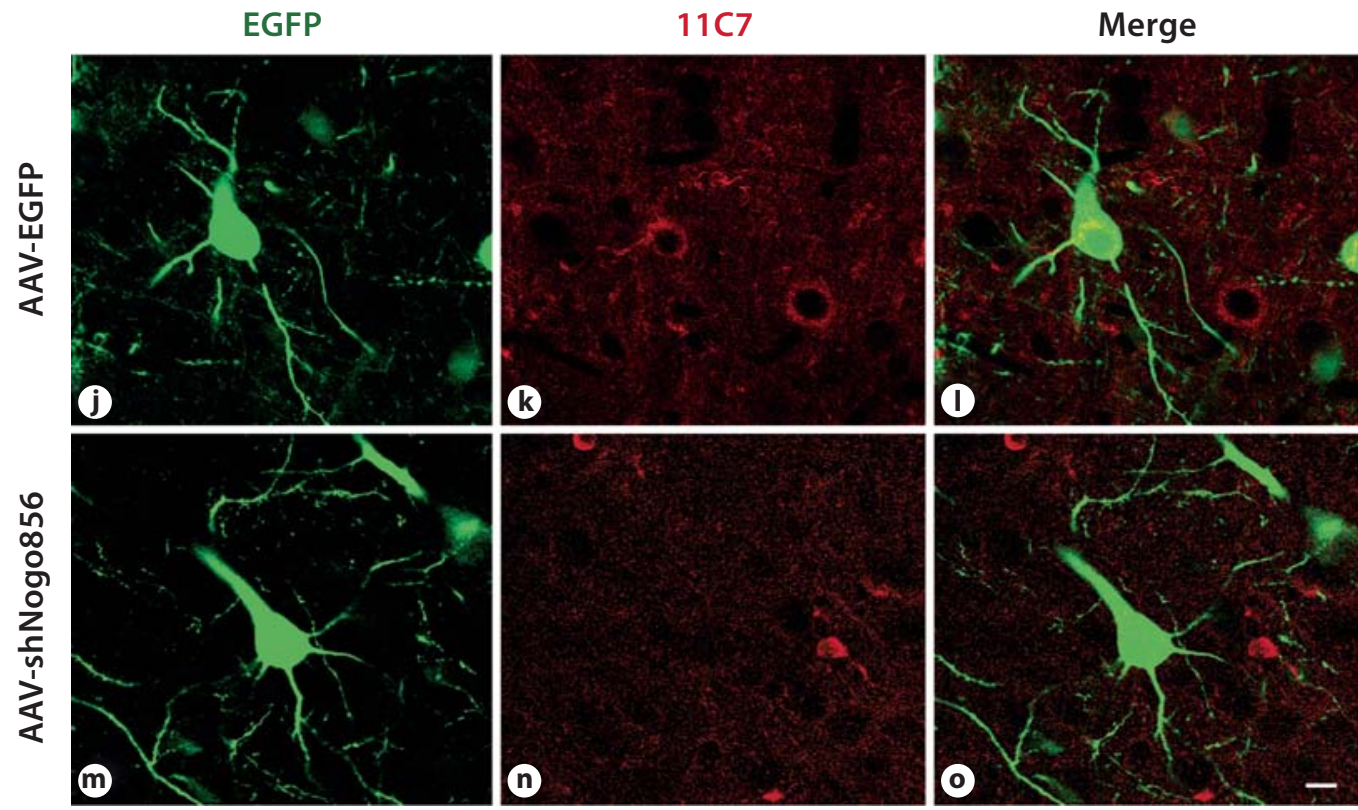

Fig. 2. Recombinant virus mediated in vitro and in vivo Nogo-A gene knockdown in neurons. a-d, $\mathbf{j}-\mathbf{I}$. When injected in the presumptive primary sensorimotor cortex of neonatal rats, AAVEGFP-transduced neurons (arrows point to examples) showed Nogo-A immunoreactivity 6 weeks after injection. However, the

AAV-shNogo856-transduced neurons showed negligible Nogo-A immunoreactivity (e-h, $\mathbf{m}-\mathbf{o})$. j-o Scanning confocal microscope images, at a higher magnification, clearly demonstrate loss of Nogo-A. Scale bar: d, h: $100 \mu \mathrm{m}, \mathbf{o}: 10 \mu \mathrm{m}$.
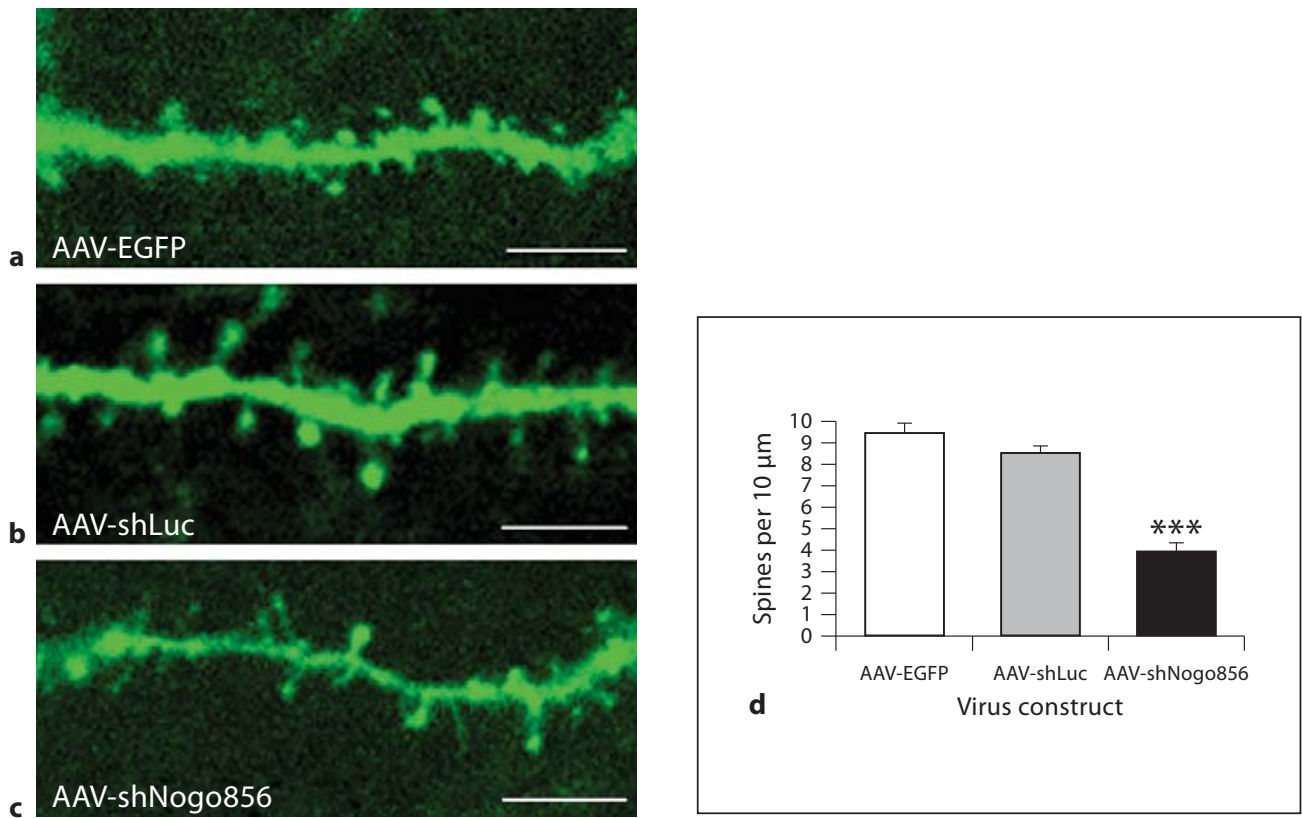

Fig. 3. Neuronal Nogo-A knockdown results in reduced dendritic spine density. The densities of dendritic spines in EGFP-transduced (a) and shLuc-transduced (b) neurons were similar to that reported in the literature for normal control rats, and not significantly different from one another. c Neurons expressing the shNogo856 siRNA demonstrated a significant reduction in den- dritic spines compared to the EGFP and shLuc control groups. d Neurons expressing the shNogo856 siRNA exhibited a significant reduction in dendritic spine density compared to both EGFP- and shLuc-transduced neurons ${ }^{* * *} \mathrm{p}<0.01$, ANOVA, mean + SEM). Scale bars: $5 \mu \mathrm{m}$. 
Fig. 4. Neuronal Nogo-A knockdown results in changes in spine morphology. a The ratio of spine head diameter to spine length significantly decreased following hairpin siRNA-mediated Nogo-A knockdown. b Transduction by AAVshNogo856 also led to an increase in the number of filopodia protrusions $\left({ }^{* *} \mathrm{p}<\right.$ 0.01, ANOVA, mean + SEM).
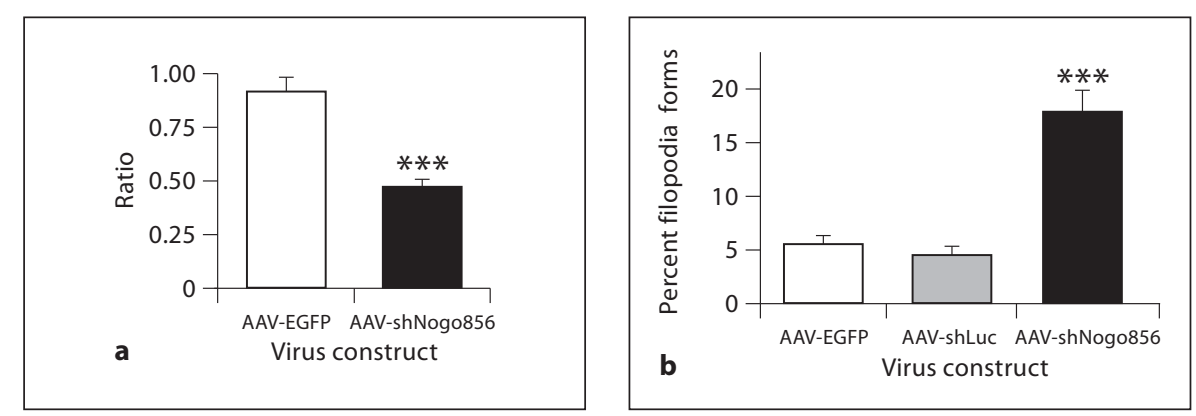

pyramidal neurons from rats transfected with AAV-EGFP had an average spine density of $9.42 \pm 1.41$ per $10 \mu \mathrm{m}$ dendrite length. Similarly, neurons in animals from the AAVshLuc group demonstrated an average spine density of 8.53 \pm 0.93 per $10 \mu \mathrm{m}$ dendrite length. Conversely, a $60 \%$ reduction in neuronal dendritic spine density was detected in neurons transduced with AAV-shNogo856, with an average spine density of $3.88 \pm 1.44$ per $10 \mu \mathrm{m}$ dendrite length; $\mathrm{p}<0.01$. In another study, the deletion of Nogo-A led to a slight increase in spine density in knockout mice as visualized in Golgi-impregnated tissue [manuscript in preparation]. These results demonstrate that postnatal Nogo-A gene knockdown influences spine density in layer $\mathrm{V}$ neocortical pyramidal neurons.

\section{Neuronal Nogo-A Knockdown in vivo Results in Alterations in Spine Morphology}

Neurons from animals transduced with AAVshNogo856 exhibited a significant increase in average spine length compared with r-AAV-EGFP animals (1.50 $\pm 0.08 \mu \mathrm{m}$ AAV-shNogo856 vs. $1.09 \pm 0.10 \mu \mathrm{m} \mathrm{AAV}$ EGFP; $p<0.05$, data not shown). This increase in average spine length was associated with a significant decrease in average spine head diameter $(0.60 \pm 0.03$ vs. $0.91 \pm 0.03$ $\mu \mathrm{m}$ AAV-EGFP; $\mathrm{p}<0.001$, data not shown) and a significant overall reduction in the ratio of spine head diameter to spine length $(0.47 \pm 0.40$ vs. $0.91 \pm 0.07$ AAV-EGFP; $\mathrm{p}<0.01$; fig. 4a). Thus, postnatal Nogo-A knockdown changes spine morphology, increasing spine length and decreasing spine head width.

Lastly, the prevalence of filopodia was examined. Neurons from the AAV-shNogo856 group showed a significant increase in the percentage of filopodial protrusions $(17.79 \pm 6.70 \% ; \mathrm{p}<0.01)$ as compared to neurons transduced with control viruses AAV-EGFP (5.53 \pm 2.24\%) and AAV-shLuc (4.42 \pm 2.60; fig. 4b), with no significant difference between the two control virus groups ( $\mathrm{p}>0.05)$.

\section{Discussion}

The results of this study indicate that postnatal suppression of Nogo-A by AAV2/8-delivered shRNA will reduce spine density in pyramidal neurons in layer $\mathrm{V}$ of the sensorimotor neocortex. Furthermore, morphological analysis of these transduced neurons showed a significant increase in filopodial type protrusions, indicating a shift to a more immature morphology in neurons lacking Nogo-A.

Nogo-A is the fourth member of a diverse family of proteins known as the reticulons [20]. Named for their cellular distribution, primarily in the endoplasmic reticulum (ER), these highly evolutionarily conserved proteins are found in all eukaryotic kingdoms. Although the complete functions of the reticulon family are not currently known, they are thought to be involved in activities as widespread as ER stress responses, cell death, vesicle formation and intracellular trafficking [21].

Nogo-A was initially isolated from CNS myelin and identified as a highly potent inhibitor of neurite outgrowth [22]. Over the past two decades, numerous studies of anti-Nogo-A antibody infusion in animal models of spinal cord injury and stroke have shown that this treatment results in functional recovery, axonal regeneration, and neuronal plasticity [2]. In particular, contralesional layer $\mathrm{V}$ neurons of the forelimb sensorimotor cortex displayed increased axonal sprouting [23], dendritic complexity, and spine density [3] following stroke and anti-Nogo-A immunotherapy in adult rats. However, after knockdown in neonatal rats, our results of decreased spine density and altered spine morphology support the hypothesis that an additional function of Nogo-A may be to promote spine development. When considering the present result of a decrease in spine density seen after Nogo-A knockdown as compared to our previous result of an increase in spine density after stroke and immunotherapy, several explanations are possible. First, the age of 
the animals was different, and decreasing the levels of Nogo-A protein in developing neurons could have led to a different result than administering the anti-Nogo-A therapy in the adult animal. Second, the axonal sprouting observed after anti-Nogo-A immunotherapy may have led to a retrograde activity- or trophic-induced increase in spine formation in the adult animals. We did not examine the possibility of an axonal response to Nogo-A knockdown in the developing CNS here, although this is currently under investigation. Third, mechanistic differences between an antibody-mediated therapy to neutralize global Nogo-A and direct loss of the protein in neurons through RNA interference cannot be ruled out.

Filopodia, which are most prevalent in early postnatal development, are also increased on pyramidal neurons in CNS conditions affecting information processing, such as Alzheimer's disease [24], schizophrenia [25], and certain forms of developmental disability [26-28]. Given this, the increase in filopodia observed after Nogo-A knockdown in the current study may indicate a decrease in synaptic function in these neurons. Furthermore, the increase in spine length and decrease in spine head width observed after Nogo-A knockdown may indicate a decrease in synaptic strength in these neurons, as spine length influences the extent of calcium isolation from the parent dendrite [29] and spine head width has been shown to correlate with spine head volume, the area of the postsynaptic density, and the number of docked presynaptic vesicles [30, 31].

Many regulators of dendritic spines have been identified by the use of siRNA, including cytoskeleton effectors [32-34] and molecules that were initially thought to be only involved in axonal guidance $[35,36]$. An earlier study reported that introduction of a shRNA against luciferase resulted in the loss of dendritic spines in hippocampal pyramidal neurons in vitro [14]. This decrease in spine density was also seen in response to foreign shRNAs that can activate interferon target genes [14]. In the present study, the average spine density of AAV-shLuc layer V-transduced neocortical pyramidal neurons was not significantly different from that of AAV-EGFP-transduced neocortical pyramidal neurons, and was also similar to spine density of neocortical pyramidal cells, as reported by others $[3,37,38]$. Therefore, in our in vivo model, an exogenous hairpin control of shLuciferase had no apparent effect on spine density.

Several mechanisms may underlie Nogo-A's role in plasticity and development, including the actions of intracellular Nogo-A, and interaction with a Nogo-66 receptor (NgR1) or integrins [39]. NgR1 has been shown to mediate changes in neuronal plasticity [40], including spine morphology, synaptic function [41], and length of neuronal stem cell neurites [42]. Integrins can interact with the amino-terminal of Nogo-A [43], and have also been implicated in dendritic spine plasticity [44, 45]. Nogo proteins have been implicated in migration of neocortical interneurons during embryonic development, neuronal polarization and neurite branching, potentially through intracellular mechanisms [5]. Indeed, intracellular Nogo-A has been reported to induce topological changes in a membranous structure, the ER [39]. While the molecular mechanism of spine loss observed here has yet to be uncovered, we propose that endogenous levels of Nogo-A expression in postnatal development are necessary for the formation and maintenance of mature spines.

\section{Conclusion}

Our results suggest that neuronal Nogo-A plays an important role in postnatal dendritic spine regulation in the cerebral neocortex. The presence of Nogo-A at multiple subcellular localizations and its differential expression patterns throughout development suggest that Nogo-A may be a multifunctional protein involved in diverse actions such as neurite outgrowth, synaptic plasticity and the regulation of spine morphology. Understanding the physiological roles of this protein may aid in the design of more effective therapeutic regimes to target Nogo-A for the treatment of various neurological disorders.

\section{Acknowledgments}

Supported by NINDS 40960, Department of Veterans Affairs, and the Loyola Neuroscience Institute (G.L.K.), and an AHA-SDG (J.L.M.). 11C7 antibody was provided by Novartis (Basel, Switzerland). mU6pro plasmid was provided by Dave Turner (www.sitemaker.umich.edu/dlturner.vectors, University of Michigan). 5EVD282 and Zac2.1-U6-luc-Zsgreen plasmids were provided by Julie Johnston (University of Pennsylvania).

References

Dev Neurosci 2010;32:313-320 319
Montani L, Gerrits B, Gehrig P, Dimou L, Wollscheid B, Schwab ME: Neuronal NogoA modulates growth cone motility via RhoGTP/LIMK1/cofilin in the unlesioned adult nervous system. J Biol Chem 2009;284: 10793-10807.

2 Gonzenbach RR, Schwab ME: Disinhibition of neurite growth to repair the injured adult CNS: focusing on Nogo. Cell Mol Life Sci 2008;65:161-176. 
3 Papadopoulos CM, Tsai SY, Cheatwood JL, Bollnow MR, Kolb BE, Schwab ME, Kartje GL: Dendritic plasticity in the adult rat following middle cerebral artery occlusion and Nogo-A neutralization. Cereb Cortex 2006; 16:529-536.

-4 Mingorance A, Fontana X, Sole M, Burgaya F, Urena JM, Teng FY, Tang BL, Hunt D, Anderson PN, Bethea JR, Schwab ME, Soriano E, del Rio JA: Regulation of Nogo and Nogo receptor during the development of the entorhino-hippocampal pathway and after adult hippocampal lesions. Mol Cell Neurosci 2004;26:34-49.

5 Mingorance-Le Meur A, Zheng B, Soriano E, del Rio JA: Involvement of the myelin-associated inhibitor Nogo-A in early cortical development and neuronal maturation. Cereb Cortex 2007;17:2375-2386.

-6 Huber AB, Weinmann O, Brosamle C, Oertle T, Schwab ME: Patterns of Nogo mRNA and protein expression in the developing and adult rat and after CNS lesions. J Neurosci 2002;22:3553-3567.

7 Josephson A, Widenfalk J, Widmer HW, Olson L, Spenger C: Nogo mRNA expression in adult and fetal human and rat nervous tissue and in weight drop injury. Exp Neurol 2001; 169:319-328

8 Caltharp SA, Pira CU, Mishima N, Youngdale EN, McNeill DS, Liwnicz BH, Oberg KC: Nogo-A induction and localization during chick brain development indicate a role disparate from neurite outgrowth inhibition. BMC Dev Biol 2007;7:32.

$\checkmark$ Aloy EM, Weinmann O, Pot C, Kasper H, Dodd DA, Rulicke T, Rossi F, Schwab ME: Synaptic destabilization by neuronal NogoA. Brain Cell Biol 2006;35:137-156.

10 Dodiya HB, Bjorklund T, Stansell J 3rd, Mandel RJ, Kirik D, Kordower JH: Differential transduction following basal ganglia administration of distinct pseudotyped AAV capsid serotypes in nonhuman primates. Mol Ther 2010;18:579-587.

- 11 Allocca M, Mussolino C, Garcia-Hoyos M, Sanges D, Iodice C, Petrillo M, Vandenberghe LH, Wilson JM, Marigo V, Surace EM, Auricchio A: Novel adeno-associated virus serotypes efficiently transduce murine photoreceptors. J Virol 2007;81:11372-11380.

12 Broekman ML, Comer LA, Hyman BT, SenaEsteves M: Adeno-associated virus vectors serotyped with AAV8 capsid are more efficient than AAV-1 or -2 serotypes for widespread gene delivery to the neonatal mouse brain. Neuroscience 2006;138:501-510.

-13 Yu JY, DeRuiter SL, Turner DL: RNA interference by expression of short-interfering rNAS and hairpin rNAS in mammalian cells. Proc Natl Acad Sci USA 2002;99:6047-6052.

14 Alvarez VA, Ridenour DA, Sabatini BL: Retraction of synapses and dendritic spines induced by off-target effects of RNA interference. J Neurosci 2006;26:7820-7825.

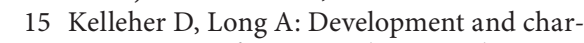
acterization of a protein kinase $C$ beta-isozyme-deficient T-cell line. FEBS Lett 1992; 301:310-314.
16 Zolotukhin S, Byrne BJ, Mason E, Zolotukhin I, Potter M, Chesnut K, Summerford C, Samulski RJ, Muzyczka N: Recombinant adeno-associated virus purification using novel methods improves infectious titer and yield. Gene Therapy 1999;6:973-985.

17 Phifer CB, Terry LM: Use of hypothermia for general anesthesia in preweanling rodents. Physiol Behav 1986;38:887-890.

18 Abramoff MD, Magelhaes PJ, Ram SJ: Image processing with image $J$ Biophotonics Int 2004; 11:36-42.

19 Harris KM, Jensen FE, Tsao B: Three-dimensional structure of dendritic spines and synapses in rat hippocampus (CA1) at postnatal day 15 and adult ages: implications for the maturation of synaptic physiology and long-term potentiation. J Neurosci 1992;12: 2685-2705.

20 Oertle T, Schwab ME: Nogo and its partners. Trends Cell Biol 2003;13:187-194.

21 Yang YS, Strittmatter SM: The reticulons: a family of proteins with diverse functions. Genome Biol 2007;8:234.

22 Caroni P, Schwab ME: Antibody against myelin-associated inhibitor of neurite growth neutralizes nonpermissive substrate properties of CNS white matter. Neuron 1988;1:8596.

23 Seymour AB, Andrews EM, Tsai SY, Markus TM, Bollnow MR, Brenneman MM, O’Brien TE, Castro AJ, Schwab ME, Kartje GL: Delayed treatment with monoclonal antibody IN-1 1 week after stroke results in recovery of function and corticorubral plasticity in adult rats. J Cereb Blood Flow Metab 2005; 25:1366-1375.

24 el Hachimi KH, Foncin JF: Loss of dendritic spines in Alzheimer's disease (in French). C R Acad Sci 1990;311:397-402.

25 Garey LJ, Ong WY, Patel TS, Kanani M, Davis A, Mortimer AM, Barnes TR, Hirsch SR: Reduced dendritic spine density on cerebral cortical pyramidal neurons in schizophrenia. J Neurol Neurosurg Psychiatry 1998;65: 446-453.

26 Huttenlocher PR: Dendritic and synaptic pathology in mental retardation. Pediatr Neurol 1991;7:79-85.

27 Kaufmann WE, Moser HW: Dendritic anomalies in disorders associated with mental retardation. Cereb Cortex 2000;10:981991.

28 Belmonte MK, Bourgeron T: Fragile X syndrome and autism at the intersection of genetic and neural networks. Nat Neurosci 2006;9:1221-1225.

29 Korkotian E, Segal M: Fast confocal imaging of calcium released from stores in dendritic spines. Eur J Neurosci 1998;10:2076-2084.

30 Harris KM, Stevens JK: Dendritic spines of CA 1 pyramidal cells in the rat hippocampus: serial electron microscopy with reference to their biophysical characteristics. J Neurosci 1989;9:2982-2997.

31 Arellano JI, Benavides-Piccione R, Defelipe J, Yuste R: Ultrastructure of dendritic spines: correlation between synaptic and spine morphologies. Front Neurosci 2007;1:131-143.
32 Tolias KF, Bikoff JB, Kane CG, Tolias CS, Hu L, Greenberg ME: The RAC1 guanine nucleotide exchange factor TIAM1 mediates EPHB receptor-dependent dendritic spine development. Proc Natl Acad Sci USA 2007; 104:7265-7270.

33 Calabrese B, Halpain S: Essential role for the PKC target MARCKS in maintaining dendritic spine morphology. Neuron 2005;48: 77-90.

34 Biou V, Brinkhaus H, Malenka RC, Matus A: Interactions between drebrin and Ras regulate dendritic spine plasticity. Eur J Neurosci 2008;27:2847-2859.

35 Aoto J, Ting P, Maghsoodi B, Xu N, Henkemeyer M, Chen L: Postsynaptic ephrinB3 promotes shaft glutamatergic synapse formation. J Neurosci 2007;27:7508-7519.

- 36 Kayser MS, McClelland AC, Hughes EG, Dalva MB: Intracellular and trans-synaptic regulation of glutamatergic synaptogenesis by EPHB receptors. J Neurosci 2006;26: 12152-12164.

37 Johansson BB, Belichenko PV: Neuronal plasticity and dendritic spines: effect of environmental enrichment on intact and postischemic rat brain. J Cereb Blood Flow Metab 2002;22:89-96.

38 Adkins DL, Bury SD, Jones TA: Laminar-dependent dendritic spine alterations in the motor cortex of adult rats following callosal transection and forced forelimb use. Neurobiol Learn Mem 2002;78:35-52.

- 39 Voeltz GK, Prinz WA, Shibata Y, Rist JM, Rapoport TA: A class of membrane proteins shaping the tubular endoplasmic reticulum. Cell 2006;124:573-586.

40 McGee AW, Yang Y, Fischer QS, Daw NW, Strittmatter SM: Experience-driven plasticity of visual cortex limited by myelin and Nogo receptor. Science (New York) 2005; 309:2222-2226.

41 Lee H, Raiker SJ, Venkatesh K, Geary R, Robak LA, Zhang Y, Yeh HH, Shrager P, Giger RJ: Synaptic function for the Nogo-66 receptor NGR1: regulation of dendritic spine morphology and activity-dependent synaptic strength. J Neurosci 2008;28:27532765.

42 Wang F, Zhu Y: The interaction of Nogo-66 receptor with Nogo-P4 inhibits the neuronal differentiation of neural stem cells. Neuroscience 2008; 151:74-81.

$43 \mathrm{Hu}$ F, Strittmatter SM: The N-terminal domain of Nogo-A inhibits cell adhesion and axonal outgrowth by an integrin-specific mechanism. J Neurosci 2008;28:12621269.

44 Shi Y, Ethell IM: Integrins control dendritic spine plasticity in hippocampal neurons through NMDA receptor and $\mathrm{Ca}^{2+} /$ calmodulin-dependent protein kinase II-mediated actin reorganization. J Neurosci 2006;26: 1813-1822.

45 Webb DJ, Zhang H, Majumdar D, Horwitz AF: Alpha5 integrin signaling regulates the formation of spines and synapses in hippocampal neurons. J Biol Chem 2007;282: 6929-6935. 